\title{
Práxis Psicoterapêutica de Estagiários de Psicologia: Análise do Relato e da Trama Narrativa
}

\author{
Luciane De Conti ${ }^{1}$ \\ Universidade Federal de Pernambuco \\ Tânia Mara Sperb \\ Universidade Federal do Rio Grande do Sul
}

\begin{abstract}
RESUMO - Este artigo apresenta uma proposta de análise narrativa das intervenções realizadas pelos estagiários de Psicologia em sua práxis psicoterapêutica. As fontes dos dados foram as transcrições das sessões de psicoterapia, conduzidas pelos estagiários com seus pacientes, associadas ao material discutido em supervisão acadêmica. A análise do texto transcrito, entendido nesse estudo como uma narrativa da prática, se deu em dois níveis: o do relato e o da trama narrativa. Os resultados explicitam os diferentes movimentos realizados pelos estagiários na tentativa de intervir em consonância com os pressupostos da psicoterapia de orientação analítica. Essas intervenções mostraram ser algumas vezes contraditórias, explicitando assim os equívocos e as vicissitudes constituintes do processo de formação do pensamento clínico.
\end{abstract}

Palavras-chave: narrativa; relato clínico; formação em psicologia.

\section{Psychotherapeutic Practice by Psychology Interns: An Analysis of Account and Narrative Plot}

\begin{abstract}
This article presents a narrative analysis proposal of the interventions made by psychology interns in their psychotherapeutic practice. The data sources were the transcripts of psychotherapy sessions conducted by interns with their patients, associated with the issues discussed in academic supervision. The analysis of the transcripts, seen in this study as a narrative of the practice, occurred in two levels: of the account and of the narrative plot. The results show the different movements carried out by the interns in their attempts to intervene according to the basic ideas of an analytically-oriented psychotherapy. These interventions seem to be, at times, contradictory, thus showing the errors and vicissitudes that are part of the clinical thinking learning process.
\end{abstract}

Keywords: narrative; clinical report; psychology degree.

A formação em psicologia apresenta em seu currículo a obrigatoriedade da realização da prática de estágio. Uma das modalidades possíveis para essa prática é a da psicologia clínica, sendo uma de suas atribuições que o aluno passe pela experiência de ocupar o lugar de terapeuta em uma prática de psicoterapia. E a universidade, como uma das instituições responsável pela formação profissional e pela proposição teórico-metodológica de ferramentas de intervenção, precisa construir diferentes dispositivos que contribuam para a reflexão acerca da práxis realizada por seus estudantes.

Nessa direção, Cifali (2000) coloca que um dos dispositivos propostos como ferramenta de trabalho na formação é o uso da narrativa, tendo em vista que ela pode contribuir para a construção de uma memória da prática. No caso específico deste estudo, essa memória foi constituída por meio dos registros escritos que os alunos em prática de estágio realizaram acerca dos atendimentos desenvolvidos com seus pacientes, em um contexto de psicoterapia. Dessa experiência resultou a elaboração de algumas ferramentas metodológicas

1 Endereço para correspondência: PG em Psicologia Cognitiva. Av. Acad. Hélio Ramos, s/n - CFCH, $8^{\circ}$ andar. Recife, PE. CEP 50670-901. Fone: (81)2126 8272,21267330.Fax: (81)21267331.E-mail: ludeconti@ terra.com.br. para a análise e compreensão do campo da ação, visando possibilitar olhares diversos sobre a práxis psicoterapêutica. Neste artigo pretendemos apresentar uma das possibilidades de análise desenvolvida por nós a partir desse registro escrito da prática. Vamos inicialmente situar o contexto em que a prática de estágio em psicologia clínica foi realizada.

O estágio ocorreu em uma instituição que acolhe crianças e adolescentes separados temporariamente ou em definitivo de suas famílias de origem. Nesse âmbito, é importante lembrar que em 1990 houve no Brasil a promulgação do Estatuto da Criança e do Adolescente (ECA, 1990), que restabeleceu à criança o estatuto de sujeito de direitos. Em relação aos abrigos, o ECA estabelece, no artigo 101, parágrafo único, que o abrigo é medida provisória e excepcional, utilizável como forma de transição para a colocação em família substituta, não implicando privação de liberdade. O ECA considerou as críticas às grandes instituições de abrigamento, procurando resgatar um olhar individualizado à criança e uma relação mais viva entre ela e seu mundo social.

O abrigo é, portanto, uma casa de passagem destinada a acolher crianças vítimas de violência intrafamiliar, de negligência ou de abandono. Abels-Eber (2000) coloca que muitas crianças que residem em abrigos traduzem seus 'traços de carência' por meio de manifestações de agressividade, de 
problemas de comportamento na escola, de instabilidade, de tendências depressivas, de problemas psicossomáticos ou de deficiências cognitivas. Esse quadro de alterações psíquicas foi possível de ser visualizado pelos estagiários em seu campo de estágio, os quais interrogaram: por que não se tornou possível a algumas dessas crianças construir uma outra 'alternativa' para suas vidas que não fosse 'adoecer'?

Alguns estudos sobre o tema permitem esboçar um caminho para tentar compreender esse processo. Abels-Eber (2000) comenta que a descontinuidade afetiva na vida dessas crianças devido a rupturas familiares, as quais elas nem sempre compreendem, é um dos fatores de perturbação da ordem psicológica, pois se soma a isso a ausência da presença de adultos em quem elas possam confiar e projetar seus desejos. Como resultado, segundo Lani-Bayle (1997), há uma dissociação entre o que a criança sente como marcas em seu corpo, ainda não representadas pelo campo da linguagem, e isto que ela escuta acerca de sua história. Assim, ela não pode expressar a história de sua vida narrativamente, porém o faz de outro modo, sob formas muitas vezes patológicas como depressão, mutismo, atraso na linguagem, disfunções motoras etc.

Isso acontece porque para que a criança possa se projetar em direção a um antes e a um depois de forma narrativa, ela precisa inicialmente ter o suporte de um outro que compartilhe a sua história. Se o que os membros da instituição contam sobre sua história não faz eco às marcas de seu corpo que são inconscientes, torna-se impossível para essa criança construir pelo menos uma versão singular acerca de sua genealogia, de sua vida. Nessa perspectiva, Lani-Bayle (1999) e Marin (1999) lembram que para muitas crianças acolhidas em instituições como os abrigos, a história genealógica pode estar inacessível, pois em geral a instituição não tem os dados dessa história. Ou quando os possuem, os profissionais tentam, muitas vezes, poupar a criança do sofrimento que a narrativa desses eventos pode lhes trazer. Porém, alerta Lani-Bayle (1999), o que não se deve fazer é mascarar ou não dizer à criança o que lhes aconteceu, ou pior, contradizer sua filiação. Ela tem o direito, caso assim o desejar, de ter acesso aos elementos disponíveis acerca de sua vida para se construir a partir deles, não somente em corpo, mas em palavras. Se não existisse tal elemento fundador de sua vida, ela não estaria onde ela está.

Convém, então, que a instituição disponibilize os meios para o sujeito se apropriar, na forma de palavras, de suas experiências de vida, e assim compor uma narrativa de vida pessoal, singular. O espaço psicoterapêutico pode se constituir em um dos campos possíveis para a construção, por parte do paciente, de sua história de vida. E é exatamente nessa direção que a prática de estágio dos alunos de psicologia no abrigo se colocou: na construção de um espaço em que as questões relativas às histórias de vida dessas crianças, a partir do ponto que elas a trouxessem e se desejassem, pudessem circular e se movimentar.

Logo, foi a partir do encontro terapeuta-paciente como prática de estágio em psicologia, cujo sentido foi discutido e elaborado no espaço da supervisão acadêmica, que o objetivo da nossa pesquisa delineou-se, a saber: analisar a composição narrativa do narrador estagiário/terapeuta a fim de visualizarmos a trama narrativa que norteou suas intervenções ao longo de sua práxis psicoterapêutica. É importante esclarecer que o eixo teórico norteador da abordagem psicoterápica desses alunos foi o de orientação psicanalítica que, conforme Green (2002), possui como objetivos a ampliação da tomada de consciência do paciente, que concerne seu modo de funcionamento, a natureza de seus conflitos, as relações com sua história e, enfim, a relação com sua palavra e com a escuta do outro.

Para atingir nosso objetivo, partimos dos registros escritos dos estudantes acerca das sessões de psicoterapia realizadas com alguns de seus pacientes. Esses registros foram considerados como narrativizações da prática, pois como coloca Escars (2002), referindo-se ao histórico de caso, "se não considerarmos o histórico do caso um mero suporte para o registro de 'fatos' clínicos, temos que levar em consideração a própria estrutura do texto, isto é, o fato de que esse texto tenha uma estrutura narrativa, que seja um relato, uma narração" (p. 36). Esses registros são narrativas porque se organizam entre uma situação inicial e uma situação final, compondo, assim, um começo, um meio e um fim. Esse encadeamento cronológico dos fatos introduz uma relação de sucessão entre eles: algo que se produz (uma ação) provoca uma reação, a qual conduz a um desfecho e a uma nova situação. Assim, a situação inicial foi transformada, conforme propõe Todorov (1978/1987).

Os formalistas russos propõem ainda que na estrutura narrativa há a dimensão do relato e a dimensão da trama (Todorov, 1965/2001). Nesse sentido, existem dois níveis a serem considerados na análise do texto escrito: o do relato e o da trama ou intriga. O relato corresponde, no nosso estudo, à historicização da sessão, ou seja, à sua cronologia. A trama, por sua vez, diz respeito às teorias nas quais se baseia aquele que escreve, ou no caso específico dessa pesquisa, nos pressupostos teóricos que embasaram e nortearam as intervenções dos estagiários junto a seus pacientes. Em nossa investigação, o foco de análise centrou-se no segundo nível que compõe a estrutura narrativa, o da trama. Porém, para circunscrevermos o nível da trama, precisamos recorrer ao nível do relato e aos dados produzidos em supervisão acadêmica. Isso aponta para a importância da escrita na formação acadêmica e para o papel da supervisão nesse processo.

\section{A Escrita da Prática}

Sabemos que escrever sobre os pacientes é uma das ferramentas cruciais na prática clínica e na formação do psicólogo (Green, 2002; Mezan, 1998). A escrita que relata a experiência é, segundo Green (2002), um primeiro passo na construção do pensamento clínico. É uma primeira forma de registro sobre a qual o estagiário poderá ordenar temporalmente os acontecimentos produzidos no terreno da ação e, a partir deles, refletir sobre a sua práxis. Isto porque a observação e a reflexão acerca da ação somente podem se dar de forma retroativa, ou seja, après coup, quando um gesto retorna à mente e se pode pensar no que se passou. A memória aqui tem um papel especial, pois uma reconstrução é inevitável (Vermesch, 1994).

O material produzido sob a forma escrita torna-se, assim, um instrumento de organização da experiência, mas também uma fonte de investigação à qual o seu autor pode recorrer, 
quando quiser, para interrogar, avaliar e até mesmo ressignificar a sua ação. A escrita é uma ferramenta que nos fornece uma visão das coisas, uma compreensão da realidade. É necessário fazer uma seleção, organizar e apresentar o material de maneira aceitável, lógica, organizada e compreensível para o outro. Como apontam Diehl, Maraschin e Tittoni (2006):

a escrita se constitui em um campo importante na formação, pois possibilita uma forma de constituição de si permeada pela intensidade da experiência e da experimentação de sua alteridade no texto lido a posteriori, produzindo uma interlocução subjetiva que auxilia na exposição objetiva para o grupo da supervisão. (p. 411)

Cifali (2000) afirma que quando reconhecemos sermos portadores de nossa prática enquanto sujeitos, aceitamos aprender a partir das dificuldades, tendo posto à prova o estatuto do erro no processo do conhecimento. Assim, podemos dizer que há um outro tempo na construção do saber, posterior ao da escrita, que é aquele em que intervêm os terceiros, cuja 'discussão' abre o confronto com o outro saber, o já conhecido sobre o paciente. É nesse momento, também, que se torna possível circunscrever as bases teóricas que nortearam as intervenções realizadas no campo da ação. $\mathrm{E}$, pois, na leitura do material escrito e na interlocução com os pares que os sentidos acerca dos equívocos produzidos na práxis podem se configurar e se movimentar. Essa abertura para o questionamento da experiência com os pares remete a pensar sobre o lugar da supervisão nesse processo como um espaço possível de alteridade.

\section{A Supervisão}

A supervisão visa facilitar para o aluno de psicologia a integração de dois aspectos constituintes da prática clínica: o conhecimento teórico e o autoconhecimento (Aguirre, Pinto, Becker, Carmo \& Santiago, 2000). Esses autores colocam que a supervisão pode ser entendida como um modelo de trabalho que realiza um atendimento indireto ao paciente. Esse modelo pode ser desenvolvido e significado de diferentes maneiras e isto é que delimitará a relação supervisor-supervisionando.

Marques (2000) diz que a supervisão não é um lugar para o supervisionando aprender uma forma de trabalhar, ou uma forma de interpretar. Ela é um espaço de criação de novas possibilidades de pensar em que se tenta desfazer a ilusão e a crença na existência de uma interpretação soberana e toda poderosa. Não se busca, portanto, estabelecer o que é certo ou errado em cada situação narrada pelo supervisionando, nem encontrar significações fechadas e absolutas para os acontecimentos psíquicos, mas sim construir enigmas que permitam novas interpretações.

A supervisão tem como eixo de investigação, segundo Band (1995), a análise do campo transferencial. Essa análise se dá a partir do relato, oral e/ou escrito, do supervisionando acerca do que ocorreu no encontro entre ele, enquanto terapeuta, e seu paciente. A supervisão almeja ser um espaço em que o estagiário busque sentido, sempre provisório, para a narrativa de seu paciente e para sua prática como terapeuta. São as marcas do terreno da ação que são introduzidas pelo supervisionando na sua narrativa que serão analisadas na supervisão. Essas marcas podem ser registradas tanto nas narrativas orais, constituídas durante a supervisão, quanto nas narrativas escritas, foco do nosso estudo, que podem ser lidas e debatidas na mesma.

Tem-se, assim, a construção narrativa do narrador terapeuta quando este é o narrador da dor psíquica do outro, o paciente, pois esse relato se constitui em retraduções, tendo em vista que as imagens percebidas e as palavras ouvidas há poucos instantes são irremediavelmente travestidas por uma nova realidade, cheia de novas imagens subjetivas (Band, 1995). Assim, uma seleção se opera perpassada pelo olhar do 'terapeuta', que interpreta a partir do seu lugar o que é importante registrar, em que ordem, em que cronologia. Nesse sentido, o que se constrói nada mais é do que somente uma versão da história, mas que permite uma primeira inteligibilidade, um instrumento a partir do qual outras versões poderão ser construídas. E é essa narrativa a unidade de análise de nosso estudo.

\section{Método}

\section{Participantes}

Participaram dessa pesquisa uma aluna do curso de psicologia de uma universidade brasileira, que estava realizando estágio de psicologia clínica em um abrigo municipal. Esse estágio foi acompanhado pela primeira autora no espaço de supervisão acadêmica. Também participaram do estudo duas crianças com 9 e 10 anos de idade, acolhidas no abrigo, em situação de atendimento psicoterapêutico pela estagiária de psicologia.

\section{Instrumentos e material}

As fontes dos dados dessa pesquisa, como colocado anteriormente, foram os textos escritos pela estagiária, associados ao material discutido em supervisão acadêmica. Cada sessão foi relatada pela estagiária sob a forma escrita de entrevista dialogada. O objetivo desse relato era que o estagiário procurasse 'transcrever' cada sessão de psicoterapia para o leitor, no caso, os supervisores local e acadêmico. O ato de transcrever pode ser definido como a conversão de dados de um meio de armazenamento para outro, sem alterar seu conteúdo original, mas efetuando as conversões necessárias para que sejam aceitos pelo meio receptor. Além desse material, as questões e reflexões produzidas pelas estagiárias acerca do estágio como um todo foram também registradas pela primeira autora no espaço da supervisão acadêmica.

\section{Procedimento}

No presente trabalho, foi utilizado um delineamento de estudo de casos múltiplos - dois estudos de caso, em que cada dupla estagiária-terapeuta/paciente constituiu um caso -, segundo o modelo proposto por Yin (1994/2001). 
Os dois casos foram conduzidos pela mesma estagiária, porém com duas pacientes distintas. Optamos por expor dois casos acompanhados por uma mesma estagiária porque assim acreditamos explicitar que a relação estabelecida entre psicoterapeuta e paciente é dialógica, bem como evidenciar as vicissitudes na formação do psicoterapeuta.

A unidade de análise principal de cada estudo de caso foi a composição narrativa escrita pelo narrador estagiárioterapeuta. Para investigar essa unidade de análise, foram considerados, conforme proposto por Todorov (1965/2001), dois níveis que compõem a estrutura narrativa: o do relato e o da trama. Para isso, observamos as repetições de uma mesma sequência de ações entre os diversos ciclos narrativos presentes nos relatos escritos das estagiárias, acrescidos do material produzido em supervisão.

A pesquisa foi realizada em um contexto de psicoterapia de orientação psicanalítica. A psicoterapia foi indicada, para as crianças selecionadas nesta pesquisa, pela equipe da instituição que as abrigava. Os atendimentos foram desenvolvidos pelas estagiárias em uma das salas localizada em uma das casas do abrigo e aconteceram uma vez por semana, com duração de 45 a 50 minutos.

A supervisão acadêmica realizou-se na clínica-escola da Universidade. Ocorreu uma vez por semana e teve duração de 1 hora e 30 minutos. Os casos selecionados foram aqueles casos cujos registros escritos foram escolhidos pela estagiária para serem lidos e analisados na supervisão acadêmica em função de dúvidas ou questionamentos que a estagiária tinha em relação ao andamento de uma sessão em particular ou ao encaminhamento do caso. Outro critério de seleção foi a duração do tratamento, ou seja, foram escolhidas as duas crianças que permaneceram em acompanhamento terapêutico pela estagiária em um período superior a 2 meses. A estagiária, a coordenadora e a psicóloga do abrigo foram informadas dos objetivos e das justificativas da pesquisa no início dos nossos trabalhos, e assinaram os termos de consentimento.

\section{Análise de dados}

Os registros escritos das sessões de psicoterapia foram analisados a partir da adaptação do modelo de análise da narrativa proposto por Todorov (1967), tendo em vista que a proposição analítica desse autor permite a visualização de como a narrativa se estrutura em termos de seu relato e de sua trama. Nesse modelo, o autor coloca que a narrativa representa a projeção sintagmática de uma rede de relações paradigmáticas. Ele esclarece que, na narrativa, a sucessão das ações não é arbitrária, mas obedece a uma certa lógica, pois existe, no conjunto da narrativa, uma dependência entre certos elementos. Ainda segundo Todorov, para seguir a intriga ou a trama é necessário ler as linhas horizontais que representam o aspecto sintagmático da narrativa e, em seguida, comparar as proposições nas colunas e buscar seu denominador comum.

Assim, partimos das narrativas escritas pela estagiária e as categorizamos, em um primeiro momento, de acordo com as suas ações, a fim de compormos o aspecto sintagmático de cada narrativa transcrita, ou seja, o nível do relato. Em um segundo momento, verificamos as sequências das ações apresentadas nas diferentes narrativas, visando compará-las e, dessa forma, visualizarmos a possível existência de uma mesma sequência de ações, o que comporia uma homologia. Uma homologia é definida por Todorov (1967) como a repetição de uma mesma sequência de ações presente em diferentes narrativas. É esse aspecto que constitui o enredo, a trama narrativa e, portanto, o foco do presente estudo.

\section{Resultados e Discussão}

Nos dois casos analisados foram encontradas diferentes homologias que obedecem ou à repetição de uma mesma lógica de ação em sequências de ações distintas ou à repetição de uma mesma ação. As repetições registradas nos casos analisados são identificadas nos exemplos citados em itálico nas tabelas 1 a 5. Descrevemos, a seguir, as homologias encontradas nos dois casos analisados, apresentando conjuntamente a discussão dos resultados encontrados em cada caso.

\section{Caso Renata-Carla ${ }^{2}$}

Carla foi acompanhada por Renata durante 4 meses. A primeira homologia foi encontrada em nove narrativas e foi definida como 'Renata pergunta: Carla responde'. Essa homologia é caracterizada pela tentativa de Renata em estabelecer um diálogo com a sua paciente, colocando para ela diferentes questões como: o motivo de estar em acompanhamento terapêutico, do que Carla pretende brincar, como foram as atividades realizadas fora da instituição. Carla responde às questões de Renata de forma sucinta e objetiva e, muitas vezes, por meio de gestos. A Tabela 1 apresenta um exemplo dessa dinâmica das ações.

A segunda homologia registrada no caso Renata e Carla aparece em cinco narrativas e foi denominada 'Renata propõe: Carla aceita'. Da mesma forma que a homologia anterior, é Renata quem inicia essa sequência de ações, pois ela propõe à Carla com que objetos e como brincar, ou seja, ela dita as regras da brincadeira. Carla, por sua vez, aceita as idéias propostas por sua terapeuta e as duas seguem a interação.

A terceira homologia foi demarcada somente em três narrativas, que foram constituídas entre Renata e Carla na metade final do tratamento. Ela apresenta uma característica inversa às homologias anteriores, pois nessa sequência de ações é Carla quem inicia a ação, propondo à Renata com que objeto brincar e como brincar. Renata aceita as propostas de sua paciente entrando no universo lúdico delineado por ela. Um exemplo dessa homologia é mostrada na Tabela 2.

A análise das homologias constituídas pela dupla terapêutica Renata e Carla mostra que, na dinâmica narrativa configurada por elas, é a estagiária/terapeuta quem toma a iniciativa de grande parte das ações e a sua paciente reage a elas. É essa lógica de ação que constitui, nesse caso, aplicações paralelas de uma mesma regra.

As homologias 'Renata pergunta: Carla responde' e 'Renata propõe: Carla aceita' podem estar demonstrando o

2 Nomes fictícios dados à estagiária-terapeuta e à paciente. Carla tinha 9 anos quando foi acolhida pela primeira vez na instituição. 
Tabela 1. Homologia Renata pergunta: Carla responde.

\section{Narrativa $1(21 / 08)$}

R. pergunta se C. sabe o motivo do tratamento.

C. responde negativamente.

R. esclarece sobre o motivo: '...está aqui por se encontrar bastante triste, quieta.'

R. esclarece sobre as regras do espaço terapêutico: '... um espaço para conversar, falar sobre as coisas que lhe estão acontecendo, que não entende. Falo sobre o significado que terá todo o seu comportamento aqui dentro... sobre os brinquedos, a organização destes... o uso da sala por outras crianças... o sigilo... que pode fazer o que desejar...'

R. observa: 'C. apresenta postura retraída, como se aquela cadeira a estivesse protegendo de algo.' 'C. permanece em silêncio, rói as unhas'.

'pedido' da paciente pelo suporte imaginário de sua terapeuta, para que a rede associativa possa se recompor e deslizar a fim de que a tessitura da intriga possa se constituir. Pois, como podemos observar em diferentes momentos desse processo terapêutico, Carla convoca Renata para brincar ou para explorar com ela os objetos. É como se ela dissesse para Renata: "preciso que tu sirvas de espelho, preciso do teu suporte". Dolto (1990) comenta que, muitas vezes, o corpo e a voz do analista funcionam como suportes imaginários necessários para o desenlace da cadeia associativa de algumas crianças. Seria uma tentativa da criança em sintonizar com os significantes do outro para poder compor a partir deles a sua trama narrativa, pois o "o espelho antecipa o ato de palavra" (Bergès \& Balbo, 1997, p. 86). Esse movimento remonta aos primórdios da constituição psíquica do sujeito, ou seja, ao estádio do espelho proposto por Lacan (1966/1999). Nesse, o outro materno insere a criança no campo da linguagem, nomeando seu corpo e, assim, antecipando para ela um corpo unificado que ela ainda não tem condições de sustentar simbolicamente sozinha. E é nesse contexto de nomeação que as narrativas são introduzidas, pois esse outro pode colocar as ações da criança, tanto as ações do passado quando as expectativas em relação ao futuro, numa sequência narrativa. E é isso que podemos formular em relação ao pedido de Carla para Renata: que Renata nomeie e encadeie provisoriamente algumas ações de Carla, a partir das quais esta poderá seguir narrativizando suas experiências.

Poderíamos dizer que o 'pedido' de Carla vai em direção à solicitação do atravessamento do outro e seria essa suposição que norteia a intervenção de Renata. Ou seja, essa suposição pode ser entendida aqui como a trama narrativa que guia a ação da estagiária e dá rumo ao fluxo do tratamento. Nessas homologias, é Renata quem toma a iniciativa da ação e isso pode estar demonstrando o seu entendimento de que Carla necessitava desse suporte e de tempo para compor a sua rede de intriga. Renata atende ao 'pedido' de Carla compreendendo que esse movimento é temporalmente necessário para que a rede associativa de sua paciente possa se constituir. Este fato foi corroborado em supervisão acadêmica por meio da observação de Renata de que Carla precisava de um suporte seu.

Há, entretanto, passagens na interlocução desempenhada pela dupla terapêutica que esboçam movimentos de Carla em desencadear uma rede associativa como, por exemplo, há narrativas em que Carla começa a brincar com os carrinhos; em que ela comenta sobre a aula de música; em que ela associa o objeto (espelho) utilizado por ela em sua brincadeira com um espelho que seu pai possuía; ou, então, em que ela começa a brincar de tiro ao alvo. Essas ações também podem ser vistas como repetições de uma mesma lógica de ação em que Carla ativamente começa, comenta ou associa algo, ou seja, ela é a agente de uma ação que desencadeia um drama narrativo. É possível unirmos essas narrativas à terceira homologia 'Carla propõe: Renata aceita', explicitada na Tabela 2, pois elas representam aplicações paralelas de uma mesma regra, o que quer dizer que Carla é quem inicia uma determinada situação e Renata reage a essa proposta de maneiras diversas.

Tabela 2. Homologia Carla propõe: Renata aceita.

\section{Narrativa $8(10 / 10)$}

R. pergunta: ‘você está feliz hoje?’ ‘o que você quer fazer hoje?’

\section{C. responde: 'hã!' 'brincar contigo!'}

R. solicita mais detalhes: 'com o que você quer brincar?'

\section{C. propõe com o que brincar: 'o rádio'}

R. aceita a brincadeira proposta por C.: 'após algum tempo, participo com ela da brincadeira de trocar os canais.'

C. para de brincar com o rádio: 'Não quero mais brincar disso!' 
Essas reações da estagiária podem ser lidas como tentativas de Renata em seguir a rede associativa de sua paciente e, com isso, seguir o método da associação livre. Assim, podemos pensar que, nesse caso, a trama narrativa que norteia as intervenções de Renata é colocar em prática o método psicanalítico. Isso porque, nessas interlocuções, Renata entra no campo semântico de sua paciente a fim de procurar ampliá-lo, porém esse processo flui de forma lenta e até mesmo gradual, muitas vezes interrompido pelas rupturas discursivas desencadeadas por Carla.

\section{Caso Renata-Andréia ${ }^{3}$}

Andréia foi acompanhada por Renata por um período de 3 meses. A primeira homologia foi encontrada em seis narrativas e denominamos 'Andréia começa: Renata relaciona: Andréia responde'. Essa sequência de ações é marcada pela iniciativa de Andréia em começar o faz de conta ou um jogo. Renata, diante dessa atitude de sua paciente, procura questionar Andréia, relacionando com a realidade alguns dados da temática do jogo simbólico ou comportamentos desta na brincadeira. Andréia, por sua vez, reage respondendo às questões colocadas pela sua terapeuta. É interessante observar que essa sequência de ações foi composta pela dupla nos três primeiros encontros terapêuticos. Um exemplo dessa homologia encontra-se na Tabela 3.

A segunda homologia corresponde somente a três narrativas. Ela foi definida como 'Andréia associa: Renata solicita: Andréia responde'. Essa sequência de ações foi composta nas sexta e sétima entrevistas e representa a ação de Andréia em associar o tema de seu faz de conta ou de seu jogo com algo da sua realidade, como a família ou um filme que assistiu. Renata responde a essa ação de Andréia solicitando a esta mais detalhes acerca da sua associação, ou seja, ela procura explorar o comentário de sua paciente. Andréia diante do questionamento de Renata, responde.

A última homologia registrada no caso Renata e Andréia foi definida 'Andréia começa: Renata interroga: Andréia responde' e está presente em oito narrativas. Nessa homologia, Andréia começa o faz de conta e Renata entra no contexto de brincadeira para seguir o diálogo com sua paciente. Renata, por exemplo, interroga Andréia sobre as atitudes e os comportamentos dos personagens do jogo simbólico. Esta responde às questões dando continuidade à brincadeira. $\mathrm{A}$ Tabela 4 exemplifica essa situação.

Essas três homologias representam a maioria das narrativas desenvolvidas por Renata e Andréia. Uma primeira observação mostra que, diferente do caso anterior, em todas as homologias é a paciente, no caso Andréia, quem inicia a ação (começa e associa), sendo a ação da terapeuta uma reação (relaciona, solicita e interroga), a qual desencadeia outra ação de Andréia (responde). Poderíamos dizer que essa tríade ação-reação-resposta delimitaria, como refere Todorov (1978/1987), aplicações de uma mesma regra. Salientamos, porém, que duas ações de Andréia correspondem a três ações

3 Andréia (nome fictício) entrou na instituição pela segunda vez quando tinha 10 anos.
Tabela 3. Homologia Andréia começa: Renata relaciona: Andréia responde.

Narrativa $8(04 / 07)$

A. pergunta: 'ainda temos tempo para jogar um jogo?'

R. responde: 'temos.'

A. começa a jogar: 'cadê aquele jogo de montar?'

R. relaciona a brincadeira com a realidade: 'você gosta de montar coisas?'

A. responde: 'gosto, eu sempre ajudava minha mãe na roça'.

R. solicita mais detalhes: 'é mesmo?' 'o que mais você fazia com a sua mãe?'

R. aponta: 'tu notou que eu te fiz uma pergunta e você ainda não respondeu?' 'e tu lembra o que eu te perguntei?'

R. esclarece sobre as regras do espaço terapêutico: 'este espaço também é para falar sobre essas coisas.'

A. pergunta: 'ainda temos bastante tempo?'

R. responde: 'já está na hora de guardarmos as coisas.'

R. observa: 'em vez de arrumar o que ela pegou, começa a organizar toda a sala, angustiada.'

R. constrói uma devolução: 'você está querendo me dizer com isto que você organizava todas as coisas na sua casa para sua mãe.'

A. responde positivamente.

de Renata. Isso quer dizer que a ação 'começar' corresponde às reações 'relaciona' e 'interroga'; a ação 'associa' corresponde à reação 'solicita detalhes'. O que as diferencia ou as unifica, ou seja, qual seria a trama narrativa que guia esse fluxo de intervenções?

As três reações de Renata vão em direção a explorar em detalhes o universo configurado por Andréia. Podemos pensar que Renata ensaia seguir a rede de significações de sua paciente, partindo do material que esta traz para, junto com ela, tentar decodificá-lo. A ação 'relaciona', por exemplo, mostra a tentativa ativa de Renata em estabelecer uma rede de associação entre os dados elaborados por sua paciente e a realidade desta. Renata busca, portanto, explorar alguns aspectos do enredo proposto por Andréia, direcionando-os diretamente à realidade da paciente. Nessa ação, Renata parte da polifonia da tessitura da intriga formulada por Andréia para associar brincadeira e realidade, o que nos leva a supor que Renata parte do princípio que o jogo infantil representa de forma indireta situações da realidade da criança. Esse fato pode ser demonstrado na narrativa 12, apresentada na Tabela 5. 
Tabela 4. Homologia Andréia começa: Renata interroga: Andréia responde. Narrativa $7(04 / 07)$

A. começa o faz de conta: '... faz um barquinho para mim?'

$R$. interroga sobre a brincadeira: 'o que você está escrevendo?' 'para quem é a carta?' ‘quando você acabar de escrevê-la, lê ela para mim?'

A. responde: 'uma carta.' 'para a senhora.'

A. solicita autorização: 'eu posso pintar tia?' 'vou usar algodão, posso tia?'

R. esclarece sobre as regras do espaço terapêutico: 'lembra que eu te disse que você pode usar tudo o que quiser na sala, não precisa me perguntar.'

A. responde: 'tá.'

A ação 'Renata relaciona', esboçada na narrativa 12 , embora apareça fora da sequência de ações 'Andréia começa: Renata relaciona: Andréia responde', evidencia a tentativa ativa da estagiária-terapeuta em 'impor' a associação do faz de conta com a realidade de Andréia. Esta reage à insistência de sua terapeuta, alertando que o contexto é de brincadeira ("é brincadeira tia"). Lebovici e Diatkine (1988) e Rodulfo (1990) alertam que a criança necessita, muitas vezes, do suporte da fantasia para poder 'falar' de seus traumas ou do suporte do objeto para desenvolver a sua rede associativa. Freud (1920/1976) coloca que o faz de conta é o espaço lúdico que a criança cria para expressar e organizar psiquicamente as situações traumáticas cotidianas e que essa ação pode ser interrompida toda vez que o conteúdo fantasiado pode 'ser lido' como sendo realidade. Poderíamos dizer que Andréia explicita, na narrativa acima descrita, a sua necessidade em utilizar o lúdico para se expressar e elaborar os seus conteúdos psíquicos e que a tentativa ativa de Renata em relacionar o faz de conta com a realidade estava impossibilitando-a de seguir associando.

Entretanto, a reação de Renata 'interroga' parece demonstrar um movimento diferente, senão inverso à sua atitude de relacionar a brincadeira com a realidade. Quando a estagiária-terapeuta interroga Andréia sobre a brincadeira, ela está exatamente 'entrando' no universo lúdico configurado pela paciente para explorar a polifonia ali presente. Esses diferentes movimentos de Renata em relação à ação lúdica de sua paciente podem ser associados ao seu relato em supervisão acadêmica em que dizia "ter dificuldade em brincar, em entender o papel do lúdico no tratamento infantil" e se interrogava: "como interpretar essa ação da criança?". Assim, essas homologias representam o seu exercício em escutar as possíveis associações da sua paciente a partir do lúdico.

Tabela 5. Ação 'Renata relaciona'.

\section{Narrativa 12 (18/07)}

A. começa o faz de conta: 'oi mana, você quer vir aqui em casa hoje?' 'eu quero conversar contigo.'

R. interroga sobre a brincadeira: 'conversar sobre o que?'

A. responde: 'sobre uma coisinha importante, depois eu te conto.' 'vê se traz o teu namorado junto.'

R. relaciona a brincadeira com a realidade: 'sua mana tem namorado?'

A. responde: 'é brincadeira, tia'.

R. responde: 'eu sei, no telefone você pediu para ela trazer...'

A. responde: 'ela tem e eu também. Você vai trazer ele junto?'

R. interroga sobre a brincadeira: 'não sei, o que você acha?' 'que festa?'

A. responde: 'eu acho que sim...' 'uma festa que vai ter depois.'

R. relaciona a brincadeira com a realidade: 'você já teve algum namorado?' 'você sabe o que é namorar' 'você tem irmãos?' 'você já foi a algum baile antes?'

A. responde: 'eu não!' 'eu sei, mas eu não tenho namorado não!' 'tenho três. Eles estão aqui.' 'eu não...'

R. constrói uma devolução: 'você me contou várias coisas hoje, como a maneira que agia em casa tendo o controle de toda a situação... algumas coisas eu não entendi bem, mas com tempo eu vou entender melhor.'

Em relação à homologia 'Andréia associa: Renata solicita detalhes: Andréia responde', podemos observar que ela também apresenta uma situação inversa à relação da homologia 'Andréia começa: Renata relaciona: Andréia responde', pois na primeira sequência de ações é Andréia quem relaciona ou associa algo do seu contexto lúdico com a sua realidade. Renata parte, então, da associação de sua paciente para 
explorar o material produzido por ela na busca de compor com Andréia os significados possíveis. Podemos concluir, então, que a relação entre as três homologias é de inversão à primeira homologia 'Andréia começa: Renata relaciona: Andréia responde'.

Esse movimento dialético demonstra a busca incessante de Renata em 'descobrir' o campo semântico de sua paciente e talvez seja essa posição que a leve a procurar decifrar os possíveis significados ocultos na rede associativa de sua paciente. Ou seja, a trama narrativa que norteou suas intervenções nessas sessões, da mesma forma que no caso anterior, foi a 'crença' de que haveria algo pronto e acabado que precisaria ser revelado. Posição diferente seria se ela entendesse a situação terapêutica como uma composição semântica fruto de um processo de construção/desconstrução de sentidos resultante do seu encontro com Andréia e vice-versa.

Renata procura desvelar os sentidos e, nesse movimento, tenta exercitar a escuta clínica rumo à associação livre, mas como ela mesma coloca: "como escutar sem pré-julgar e sem utilizarmos o imperativo institucional se fazemos parte da equipe e somos informadas que a criança que acompanhamos fugiu ou está agressiva? Como compor a história dessa criança se nada sabemos sobre ela?’. Essa última questão revela o inquietante lugar do não saber do psicoterapeuta e, nesse caso, poderíamos pensar que Renata ainda está se movendo guiada pela ideia de que há como saber algo $a$ priori sobre o paciente.

\section{Considerações Finais}

O presente estudo procurou demonstrar a riqueza do uso da narrativa como dispositivo na formação do psicólogo e a importância de desenvolvimento de metodologias de análise da mesma. A metodologia exposta aqui se restringe a uma análise formal da narrativa, tendo em vista que se circunscreve a sua organização estrutural. Sabemos, como aponta Ricoeur (1983/1994, 1984/1995), que há limites nessa leitura estrutural da narrativa, pois ela deixa escapar o aspecto semântico da composição narrativa, salientando a sua cronologia temporal linear (De Conti \& Sperb, 2009). Porém, essa escolha analítica permitiu visualizarmos, a partir dos registros escritos e, portanto, restritos ao recorte do estagiário, como se organizaram as ações desse estagiário/ terapeuta em sua práxis psicoterápica, demonstradas no estudo sob a forma de homologias.

A descrição das homologias possibilitou ao estudante, bem como ao seu supervisor, uma leitura do modus operandi preponderante nas intervenções desse estagiário. Isso porque elas evidenciaram as repetições realizadas pelo estagiário em suas intervenções frente a seus pacientes, permitindo, com isso, uma reflexão sobre sua práxis. Nesse sentido, como colocamos na introdução deste artigo, a escrita da prática demonstrou ser um valioso instrumento de registro e de análise da práxis do estudante, pois o ato de escrever possibilitou a ele um primeiro distanciamento do campo da ação. Por sua vez, a leitura desse registro e a análise narrativa da mesma viabilizaram um outro olhar sobre a prática, compondo assim um segundo distanciamento marcado pela reflexão sobre a ação.

É nesse aspecto que reside a contribuição deste estudo, na proposição de uma metodologia de análise do relato e da trama narrativa, neste caso, da narrativa do atendimento clínico. Como percebemos na análise dos dados, as intervenções se mostraram estar embasadas em uma trama narrativa constituída a partir do arsenal teórico e metodológico composto pelo estagiário e seus pares ao longo de sua formação. A leitura da trama narrativa também evidenciou os diferentes movimentos realizados pelos estagiários na tentativa de 'compreender' a narrativa de seus pacientes e, dessa forma, intervir na direção interpretada por eles como condizente com os pressupostos da psicanálise. Esses movimentos se mostraram algumas vezes contraditórios, explicitando os equívocos constituintes no processo de formação do pensamento clínico.

Ou seja, algumas intervenções configuradas pelas duplas no encontro terapêutico caminharam em direção à polifonia de sentidos, possibilitando, assim, a ressignificação de versões já dadas acerca da história de vida do paciente. Essa abertura de sentido é constituída pelas brechas discursivas compostas na práxis terapêutica e 'permitidas', ou seja, não preenchidas de sentido pelo estagiário. Como aponta Guirado (2000), “são esses pequenos lugares, esses pontos de ruptura do discurso que permitem, muitas vezes, entrar nos conflitos..." (p. 58). Porém, podemos observar também que algumas ações desenvolvidas pelas estagiária-terapeuta produziram um fechamento de sentido. Essas intervenções se constituíram em repetições do terapeuta marcadas pela sua dificuldade em entrar no universo narrado do paciente e de se desprender de ideias pré-concebidas e de saberes préestabelecidos delimitados nos referenciais teóricos analisados em sala-de-aula.

Esse confronto com o não saber, que pode ser lido nesse caso como o não saber terapêutico e, nesse sentido, do uso das técnicas, movimenta e, em outros momentos, imobiliza a trajetória dos estagiários. Dar-se conta que não se sabe sobre e que o saber construído é polifônico e, por isso, os saberes constituídos na práxis de cada um são provisórios, relativiza os saberes elaborados até então pelo psicólogo em formação. Isso exige a desconstrução dos nossos saberes pré-concebidos e a necessidade de seguirmos compondo possibilidades semânticas por meio da elaboração de diferentes ferramentas para a reflexão da práxis acadêmica, em que a análise narrativa é só uma dessas possibilidades.

\section{Referências}

Abels-Eber, C. (2000). Enfants placés et construction d'historicité. Paris: L'Harmattan.

Aguirre, A. M. de B., Pinto, E. B., Becker, E., Carmo, H. M., \& Santiago, M. D. E. (2000). A formação da atitude clínica no estagiário de psicologia. Psicologia (USP), 11, 29-48.

Band, Ar. (1995). Supervisão: A permanente fugacidade do sentido buscado. Pulsional, 78, 6- 18.

Bergès, J. \& Balbo, G. (1997). A criança e a psicanálise. Porto Alegre: Artes Médicas. 
Cifali, M. (2000). Démarche clinique, formation et écriture [Material pedagógico apresentado no Seminário Écritures, no curso Ciências da Educação]. Université de Nantes, França.

De Conti, L., \& Sperb, T. M. (2009). A composição de narrativas pela dupla terapeuta-paciente: uma análise de sua organização e de sua sequência de ações. Psicologia: Reflexão e Crítica, 22, 119-127.

Diehl, R., Maraschin, C., \& Tittoni, J. (2006). Ferramentas para um psicología social. Psicologia em Estudo, 11, 407-415.

Dolto, F. (1990). Séminaire de psychanalyse d'enfants 2. Paris: Éditions du Seuil.

Escars, C. J. (2002). O histórico de caso e a insuficiência da trama. Ágora, $V, 33-44$.

Estatuto da Criança e do Adolescente - ECA (1990). Lei no. 8.069, de 13 de julho de 1990.

Freud, S. (1976). Além do princípio do prazer (C. M. Oiticica, Trad.). Em J. Salomão (Org.), Edição standard brasileira das obras psicológicas completas de Sigmund Freud, Vol. 8 (pp. 17-90). Rio de Janeiro: Imago. (Trabalho original publicado em 1920)

Green, A. (2002). La pensée clinique. Paris: Éditions Odile Jacob.

Guirado, M. (2000). A clínica psicanalítica na sombra do discurso. Diálogos com aulas de Dominique Maingueneau. São Paulo: Casa do Psicólogo.

Lacan, J. (1999). Écrits I. Paris: Éditions du Seuil. (Trabalho original publicado em 1966)

Lani-Bayle, M. (1997). L'histoire de vie généalogique. D'edipe à hermès. Paris: L'Harmattan.

Lani-Bayle, M. (1999). L'enfant et son histoire. Vers une clinique narrative. Ramonville Saint-Agne: Editions Erès.

Lebovici, S., \& Diatkine, R. (1988). Significado e função do brinquedo na criança. Porto Alegre: Artes Médicas.
Marin, I. da S. K. (1999). Febem, família e identidade: O lugar do outro (ed. rev.). São Paulo: Escuta.

Marques, S. F. (2000). Narrativa e supervisão na psicanálise. Psychê Revista de Psicanálise, IV, 105-115.

Mezan, R. (1998). Escrever a clínica. São Paulo: Casa do Psicólogo.

Ricoeur, P. (1994). Tempo e narrativa. Tomo I (C. M. César, Trad.). Campinas: Papirus. (Trabalho original publicado em 1983)

Ricoeur, P. (1995). Tempo e narrativa. Tomo II (M. Appenzeller, Trad.). Campinas: Papirus. (Trabalho original publicado em 1984)

Rodulfo, R. (1990). O brincar e o significante: um estudo psicanalítico sobre a constituição precoce. Porto Alegre: Artes Médicas.

Todorov, T. (1967). Littérature et signification. Paris: Larousse.

Todorov, T. (1987). La notion de littérature et autres essais. Paris: Éditions du Seuil. (Trabalho original publicado em 1978)

Todorov, T. (2001). Théorie de la littérature. Textes des formalistes russes. Paris: Éditions du Seuil. (Trabalho original publicado em 1965)

Vermesch, P. (1994). L'entretien d'explicitation. Paris: ESF.

Yin, R. K. (2001). Estudo de caso. Planejamento e métodos (D. Grassi, Trad.). Porto Alegre: Bookman. (Trabalho original publicado em 1994)
Recebido em 16.12.2008

Primeira decisão editorial em 03.12.2009

Versão final em 17.12.2009

Aceito em 11.01.2010 